\title{
Coaching from a Distance: Exploring Video-Based Online Coaching
}

\author{
Cynthia Carson \\ Jeffrey Choppin \\ Warner School of Education, University of Rochester, USA
}

\begin{abstract}
This study explored an innovative coaching model termed video-based online video coaching. The innovation builds from affordances of robot-enabled videorecording of lessons, accompanied by built-in uploading and annotation features. While in-person coaching has proven effective for providing sustained support for teachers to take up challenging instructional practices, there are constraints. Both logistical and human capacity constraints make in-person coaching difficult to implement, particularly in rural contexts. As part of an NSF-funded project, we studied nine mathematics coaches over four years as they engaged in video-based coaching with teachers from geographically distant, rural contexts. We adapted a content-focused coaching model that involved a collaborative plan-teach-reflection cycle with synchronous and asynchronous components. The planning and debriefing sessions were done synchronously via Zoom, while the teaching and initial video reflection on teaching via annotations were done asynchronously. We focused on the coaches' practices in each part of the coaching cycle by analyzing interviews, surveys, annotations of the video, and transcripts of the planning and debriefing sessions. We found that: features of the online environment enabled the coach-teacher pairs to collaboratively discuss the mathematics and how students engaged with the mathematics; the coach used video and annotations to help teachers reflect on specific aspects of their practice; and the coach-teacher pairs formed trusting and productive relationships despite not having met in-person during the duration of their work together. Our findings showed that the online platform is not only an effective implementation for coaching, but also affords new opportunities for teacher reflection and evidence-based discussions.
\end{abstract}

Keywords: Video-based online coaching, content-focused coaching, annotations

Carson, C., \& Choppin, J. (2021). Coaching from a distance: Exploring video-based online coaching. Online Learning, 25(4), 104-124. DOI: 10.24059/olj.v25i4.2881 
This study explores an innovative coaching model that we termed video-based online coaching. The innovation builds from affordances of robot-enabled videorecording of lessons, accompanied by built-in uploading and annotation features. Mathematics coaching provides an individualized and sustained approach to support teachers; in-person coaching has been effective in supporting teachers to take up challenging instructional practices (Gibbons \& Cobb, 2017; Russell et al., 2020). However, in-person coaching entails logistical constraints and a level of human capacity that makes it difficult to implement, particularly in rural contexts. The considerable literature on online learning is limited in terms of the nature and efficacy of online video-based coaching. The literature on online video-based coaching is situated primarily in medical education and sports, fields that emphasize mastery of advanced technical skills. Mathematics teaching, by contrast, involves complex interactions among students, content, and context (Cohen \& Ball, 1999), making it a substantively different environment in which to conduct and research video-based online coaching.

As part of an NSF-funded project, we studied nine mathematics coaches over four years as they engaged in video-based online coaching with teachers from rural contexts who were located in areas geographically distant from the coaches. We adapted a content-focused coaching model that involved a collaborative plan-teach-reflection cycle with synchronous and asynchronous components (see Choppin et al., (in press) for a fuller description of the broader project and the video based online coaching model).

\section{Literature Review}

We begin by offering a broad overview of the research on online learning, followed by a focus on the research pertaining to online video coaching in fields outside of mathematics education and, finally, a summary of the research on online coaching in mathematics education, including the use of annotations as a tool for reflection.

\section{Online Learning and Professional Development Teacher Education}

A dearth of research exists on synchronous online professional development in mathematics education, despite the emergence of online platforms and learning environments (Johnson et al., 2018; Keengwe \& Kang, 2012; Means et al., 2009). Furthermore, there is a lack of online professional development contexts that involve teachers in sustained, intensive reflection on their practices; this has contributed to weak positive outcomes in terms of changing teachers' practices (cf. Fishman et al., 2013). Furthermore, Sing and Khine (2006) found factors that make it difficult for teachers to engage in complex forms of learning in an online context, such as teachers' roles as implementers rather than producers, cultural norms where disagreement is seen as confrontational, and the cognitive demands of teaching.

\section{Online Video Coaching}

A recent development in several fields, including sports and, more recently, medicine, is video-based coaching (Knight et al., 2012). In medicine, video-based review helps doctors improve their practice in such areas as surgery and trauma resuscitation (Hu et al., 2012; Pradarelli et al., 2021; Scherer et al., 2003). Hu and colleagues reported that surgeons of varying levels of experience found video coaching helpful to reflect on and improve their practice, and that video coaching was much more aligned with a continuous improvement model than traditional forms of professional development in medicine. Furthermore, they explained that recent advances make it easier to notate video data to document and reflect on performance, making video coaching scalable. Elite athletes have a longer history of engaging in reflective 
practices involving coaching that integrates video-based review. The use of video feedback as part of coaching has been used to improve the performance of athletes in sports such as gymnastics and swimming (Boyer et al, 2009; Wilson, 2008).

Correnti et al. (2021) studied an online coaching model consisting of an online workshop followed by online content-focused (literacy) coaching cycles. In this study, teachers first engaged in an online course focused on developing and introducing teachers with models for enacting dialogic text discussions in their classrooms. Following the course, teachers engaged in coaching cycles consisting of planning phone calls, video-recorded instruction, analysis of the videos, and post-lesson phone calls. Correnti and colleagues reported that teachers were able to develop more effective discussion facilitation practices, resulting in increased student engagement. Correnti and colleagues claimed these findings suggest that the model was effective in developing teachers' adaptive expertise through an online coaching model.

The literature on coaching in mathematics has mostly focused on the impact of coaching on teachers' practices (Kraft \& Hill, 2020) or student achievement (Campbell \& Malkus, 2011), leading to calls to focus more on the details of the interactions between coaches and teachers (Gibbons \& Cobb, 2016). Online coaching models have emerged in conjunction with the increased access to online platforms and expanded interest in coaching (Francis \& Jacobsen, 2013; Vrasides \& Zembylas, 2004). Online coaching models have the potential to address persistent logistical and resource challenges that arise with in-person coaching, such as scheduling meetings at mutually convenient times, observing lessons in person, and accessing the requisite material and human resources, especially in rural contexts (Choppin et al., 2020; Dede et al., 2009). Online coaching models utilize video to engage teachers in coach-guided reflection on instructional practices (Correnti et al., 2020; Kraft \& Hill, 2020). However, there is limited research on online coaching in mathematics education.

In mathematics education, Kraft and Hill (2020) developed an online coaching model that utilized the Mathematical Quality of Instruction (MQI) observational instrument and video to support teachers developing ambitious mathematics instruction. This model consisted of iterative cycles where coach and teacher view and analyze video clips of the teachers' instruction, as well as exemplar clips. Kraft and Hill reported that the coach-guided analysis of the video clips was effective in supporting teachers to shift their own instructional practices to align with the MQI framework. Furthermore, Kraft and Hill reported that online coaching is a less expensive and scalable alternative to in-person coaching and provides a way to connect teachers with coaches with expertise in their content area and grade level.

\section{Use of Video Annotations as a Tool for Reflection in Teacher Education}

Our focus on video annotations builds from research in which video has emerged as a prominent medium to develop teachers' capacity to reflect on their own practice (Borko et al., 2008; Calandra et at., 2007; Gaudin \& Chalise, 2015; Rich \& Hannifan, 2008; van Es \& Sherin, 2002). The use of video is typically accompanied by activities in which the viewer records their reflections in writing and often includes tagging or annotating the video (Prusak et al., 2010; Stockero et al., 2017; Walkoe, 2015). Users stop the video when they notice something relevant to their goals for viewing; these moments have been termed "call outs" (Frederiksen et al., 1998), "stopping points" (Jacobs \& Morita, 2002), or "critical incidents" (Calandra et al., 2009). We use the term "annotations" to label the artifacts of this practice; furthermore, we see annotations as a bridge between asynchronous reflection and synchronous coaching interactions. 
In this study, we addressed two concurrent gaps in the literature. First, we addressed the need to further elaborate how coaches interact with teachers during a coaching cycle (Gibbons \& Cobb, 2016, Stein et al., 2021). Second, we addressed the need to study how online coaching models afford or constrain coaching practices, particularly with respect to content-focused coaching. The questions we posed were:

1. What are the coaching practices related to planning mathematics lessons in online video coaching?

2. What are the coaching practices related to reflecting on enacted mathematics lessons in online video coaching?

In the discussion section, we address how the coaching practices explored in the two research questions were afforded or constrained by the online environment.

\section{Our Video-based Online Coaching Model}

We adapted an in-person version of a content focused coaching model (West \& Staub, 2003) that we conducted online so that we could work with teachers in rural areas. Contentfocused coaching prioritizes mathematical content knowledge and student understanding of the content throughout three phases of a coaching cycle: co-planning, enactment of the co-planned lesson, and a post-lesson discussion.

In our online model, the coach and teacher co-planned a lesson using Zoom, after which the teacher enacted the lesson using a Swivl robot and iPad to video-record the lesson, and then the coach and teacher met via Zoom to reflect on the lesson. Using the Swivl software, a video of the lesson was uploaded automatically to a shared library, where coach and teacher viewed and annotated the video before the post-lesson Zoom reflection meeting. See Figure 1 for a visual of the model.

Figure 1

Online Video Coaching Model

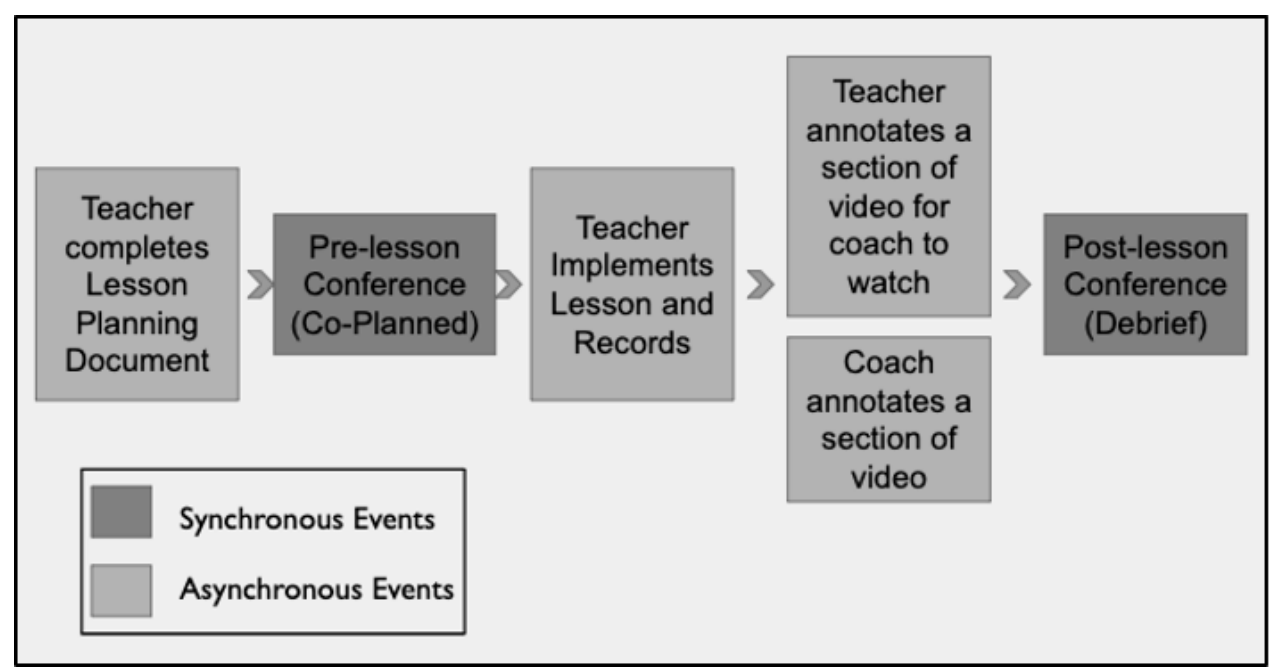




\section{Methods}

We studied nine coaches working with 18 middle grade mathematics teachers who worked in rural contexts. Seven of the coaches had no experience with online coaching prior to this project, though eight of the coaches had experience with in-person coaching. Coaches were selected based on their past experiences as in-person coaches. Coaches who had in-person coaching experience had coached for the same organization and were well known to the project personnel. The ninth coach, who was also well known to the project personnel, was selected based on her previous experience as a professional development provider. The ninth coach was beginning her first year as a coach in her current school district at the start of the study. Coaches were thus a convenience sample. See Table 1 for an overview of the coaches.

Table 1

Coach Experience at the Start of the Study

\begin{tabular}{cccc}
\hline Coach Name & $\begin{array}{c}\text { Years of Experience } \\
\text { Coaching in Mathematics }\end{array}$ & $\begin{array}{c}\text { Years of Online Coaching in } \\
\text { Mathematics Experience }\end{array}$ & $\begin{array}{c}\text { Years of Experience } \\
\text { Teaching Mathematics }\end{array}$ \\
\hline Bishop & 2 & 1 & 28 \\
\hline Hale & 1 & 0 & 10 \\
\hline Riess & 0 & 0 & 15 \\
\hline Whilton & 4 & 0 & 15 \\
\hline Alvarez & 3 & 0 & 28 \\
\hline Lowrey & 6 & 1 & 6 \\
\hline Lenore & 10 & 0 & 4 \\
\hline McFarland & 4 & 0 & 36 \\
\hline Braithewhite & 24 & 0 & 6 \\
\hline
\end{tabular}

We based our analysis on two data sources related to pre-lesson activities and two data sources related to post-lesson activities. Data sources for pre-lesson activities were transcripts from the planning sessions and interviews with coaches regarding their coaching practice. Data sources for post-lesson reflection were annotations made by the teachers and coaches, and interviews with coaches about their annotation practices. Below, we divide the discussion of our analysis into two sections, with one section focused on coaching practices that occurred before the teaching of the lesson and the second focused on the post-lesson reflection process.

\section{Analysis of Pre-Lesson Coaching Practices}

To characterize coaches' practices, we analyzed interviews with coaches about their practices related to specific coaching cycles. In the interviews, coaches described their preparation for the coaching cycle and how they structured their interactions with the teacher. 
We identified common practices across the set of coaches and how these practices were afforded or constrained by working in a fully online environment.

To analyze the interviews, we initially parsed interviews into stanzas (Miles et al., 2014) that typically contained a question and the participant response. Stanzas were then sorted into four categories based on the content of the text: practices related to the pre-lesson conference; practices related to the post-lesson conference; differences between online and face-to-face coaching, and coaching resources. The first category, practices related to the pre-lesson conference, is the focus of the analysis and findings in this paper Stanzas pertaining to this category were further divided according to three themes: coaching practices; challenges coaches faced when enacting these coaching practices; and purposes that coaches identified for their actions.

\section{Analysis of Post-Lesson Coaching Practices}

For the post-lesson reflection, we focused on annotations and coaches' interviews around them. First, we describe our analytical process for coach interviews, which were parsed into stanzas of roughly paragraph length by two members of the project. These two researchers generated a consensus summary of the stanzas; these summaries, in turn, were parsed into themes related to the coaches' annotation processes and their purposes for the annotations. A third researcher then refined those themes and grouped them into the following categories: purpose of the annotations for the debriefing discussion and nature of content of the annotations. These two broad categories were then broken into subcategories, as reported in the results in Table 1. Categories and subcategories were associated with the principles of content-focused coaching in addition to emergent themes.

We coded annotations by content and stance. To code for stance for the teacher, we used the codes report, describe, evaluate, and interpret. These themes were adapted from the literature on noticing (cf. van Es \& Sherin, 2008). Report, describe, and evaluate represent lower-level noticing, where the teacher primarily marks a moment; by contrast, interpretation involves higher-level noticing, because it makes a connection between the moment and a pedagogical principle. In terms of coaches' annotations, we analyzed the stance according to two broad categories. One category included the themes describe, evaluate, and interpret, similar to themes used for teachers. The second category characterized whether the coach's suggestion was in the form of direct assistance (suggest or explain) or invitational (elicit) (see Gillespie et al., 2019 and Ippolito, 2010, for a fuller description of this distinction). Two coders initially coded annotations according to content and stance as described above. These coders met and arrived at a consensus. Subsequently, a third researcher revisited the codes, making a small number of changes that represented a refinement of the categories. These changes were then shared with the original coders, who agreed with the revised codes.

\section{Results}

We organized results based on the two research questions. We begin with findings related to coaches' practices regarding lesson planning with the teacher, and then discuss findings pertaining to the post-lesson reflections between coach and teacher.

\section{Coaching Practices Related to Planning the Lesson}

We identified three sets of practices coaches used to support teachers in planning the lesson and which reflect content-focused coaching. Content-focused coaching focuses on the mathematical goals of the lesson, the ways the design of the lesson addresses those goals, and the 
ways the lesson design will support students to engage with the mathematics. The first two sets of practices, getting familiar with the lesson and creating a roadmap for the pre-lesson conference, describe how coaches prepared themselves for the planning meeting with teachers. The third set of practices, conducting the pre-lesson conference, involved what the coach did during the planning meeting.

\section{Getting Familiar with the Lesson}

All nine coaches familiarized themselves with the lesson in advance of the planning meeting. One coach, Reed (all names are pseudonyms), explained that getting familiar with the lesson helped her to collaborate with the teacher as a planning partner and to engage the teacher in nuanced discussions of lesson content. Getting familiar with the lesson entailed two practices: reviewing lesson materials and unpacking the mathematics of the lesson. These practices entailed the use of digital materials provided by the teacher using a template designed to compensate for the lack of face-to-face meetings. We describe the template in more detail below.

Reviewing lesson materials. All nine coaches reviewed lesson materials in advance of the planning meeting. Given that our coaches did not have in-person access to the teachers, they created a digital lesson plan template to gather information about the upcoming lesson from the teacher. The template included descriptions of students' prior experiences with the topic, the mathematical content of the lesson, student learning goals, lesson activities, desired evidence of student understanding, challenges teachers anticipated during the lesson, and teachers' personal pedagogical goals for the lesson. Hansen explained how the template familiarized him with the teacher's intention for the lesson: "The lesson planning document really changed things because now you have this very clear insight into the mathematics goals, the lesson they were planning, their own goals" (Coach Interview). Harper described the usefulness of the lesson planning document, stating "the shared Google lesson plan was really helpful because, since we are online, it gave us a common document to look at" (Harper, Coach Interview). Harper further described the necessity of having these materials in order to conduct a productive meeting, explaining that it provided a means to review the lesson and goals, stating:

I get a chance to review the lesson and think about some of the things, in terms of the mathematics goals. Is the goal going to be more procedural or conceptual? Think about what opportunities will students have for thinking, reasoning, and engaging in problemsolving? (Harper, Coach Interview)

Unpacking the mathematics of the task. Six coaches explicitly mentioned that they solved the task themselves in order to understand the mathematics and to anticipate potential student strategies and challenges the teacher was likely to encounter. This preparation helped them engage the teacher in a productive discussion of the lesson. Mason stated:

The first thing I do is the task that was given to me by the teacher as-is. However, they gave it to me, so whether it be a module lesson or it's an actual more high-cognitive, onequestion task, I sit and do it for myself. Then I also try to anticipate ways kids might approach it or misconceptions. (Mason, Coach Interview)

Brown shared how doing the mathematics of the task helped her think through ways students might approach the task. 
I always do all of the mathematics first. I ask them to send me their lesson plan and any materials, any problem sets that they think they're going to use, or whatever, the exit ticket that they're thinking of using. The first thing I always do is just dive right into the mathematics, and as I'm doing the mathematics I already start to think about different ways kids might approach it or think about—just anticipate [student approaches]. (Coach Interview)

The coaches felt their familiarity with the mathematics and tasks in the lesson materials was essential to prepare for the planning meeting with the teachers, especially given their goal to create a shared lesson plan.

\section{Creating a Roadmap for the Planning Meeting}

The second set of practices focused on the coaches developing a blueprint to guide the planning meeting. Coaches prepared prompts to push teachers' thinking about the mathematical goals, the design of the lesson, anticipated student strategies, and challenges the teacher was likely to encounter. These prompts included questions around the what, why, who, and how of the lesson. Turner described building a set of questions based on the teacher's goals:

There are questions I want to ask. Like, what is important about this particular lesson? How does this relate to big ideas? Those may not happen every time, but how that starts to happen. I think it's some basic questions, but then a lot of it goes back to what it is that the teachers are trying to get out of the coaching. (Turner, Coach Interview)

Reed used the lesson plan template to guide her preparation for the meeting, saying the document grounded the planning discussion in the teachers' ideas rather than what the coach thought should happen.

These two sets of practices - getting familiar with the lesson and creating a roadmap for the planning meeting - relied heavily on the teacher providing information using the digital lesson planning template. Though in-person coaching models have similar protocols, the development of this particular protocol was necessitated by the lack of in-person contact between teacher and coach. The digital template provided an efficient way for the teacher to share lesson information with the coach in advance of the planning meeting. In the planning meeting, teacher and coach viewed the document simultaneously, which resulted in more specific and productive conversations about the lesson goals, student strategies, and possible teacher responses. Similar to other aspects of the model, we found no loss in the robustness of the planning discussions and coach-teacher interactions by operating in a strictly online context.

\section{Conducting the Pre-Lesson Conference}

The third set of practices entailed the ways coaches engaged teachers during the prelesson conference. This involved two practices, developing goals for student understanding and anticipating student thinking and teacher responses, that represent core principles in content focused coaching. Adapting to the online environment was an initial concern for coaches as they engaged in developing goals and anticipating student strategies with teachers, and they developed ways in the online environment to compensate for the lack of face-to-face interaction.

\section{Developing Mathematical Goals for Student Understanding}


A key feature of content-focused coaching is supporting the teacher to articulate mathematical goals that involve connections between the mathematical content, the task or activity planned for the lesson, and the big mathematical ideas embedded in the mathematical goals. Brooks described the conversations with the teacher as an opportunity to explore teachers' thinking about goals and their connection to learning:

It [the lesson planning document] does give you some insight about where they [the teacher] are. You can get some ideas in advance and think, ":Okay, well, their goals really aren't very clear, so I really want to focus on what it is you're really trying to accomplish in this particular lesson?" If they have some pretty decent goals, they may not be expressed well, but we can work on them. We can work on changing how we express them in terms of knowing and understanding. (Brooks, Coach Interview)

Coaches indicated that teachers often wrote goals that were too broad and conflated action (e.g., completion of a task) with understanding. Teachers often relied on curriculum materials to identify lesson goals rather than write their own goals. Coaches indicated that by pushing teachers to consider various student strategies and intended learning outcomes they were able to support teachers to think more explicitly and productively about goals. Coaches stated that doing so helped teachers understand the difference between a performance goal (e.g., being able to perform a specific algorithm) and a learning goal. Coaches found that discussion around goals in the planning meeting was largely unaffected by conducting it via Zoom given the practice of simultaneously viewing the planning documents and other lesson artifacts during the meeting.

\section{Anticipating Student and Teacher Responses}

Coaches pushed teachers to describe anticipated student approaches and what those approaches revealed about students' understanding of the big mathematical ideas. These discussions consisted of anticipating various solution strategies as well as misconceptions the students might have. Displaying and discussing student strategies were initially challenging in the online environment; when coaches and teachers meet face-to-face, they can quickly generate student strategies on paper. However, coaches referenced their pencil and paper drawings of possible solutions by holding up their mathematics work up to the camera for the teacher to see. On other occasions, coaches and teachers shared their math drawings through Google Draw files, which allowed for collectively generated drawings that both coach and teacher could add to, edit, and discuss in the pre-lesson meeting.

\section{Coaching Practices Related to Reflecting on the Enacted Lesson}

We begin by summarizing the multiple purposes we observed regarding the annotations that emerged from our analysis. We then describe in more detail the findings from coach interviews and teacher and coach annotations that support these purposes.

\section{Purposes for the Annotations}

We observed multiple and important purposes in terms of (1) allowing teachers to reflect on their own practice; (2) allowing coaches to understand teacher reflection on the lesson; (3) providing an asynchronous opportunity for the coach to respond to the teacher; and (4) providing a list of topics and questions for the debriefing meeting. We discuss these purposes in detail below.

First, a critical facilitator for teacher reflection was the video of the lesson. One of the most notable aspects of the Swivl technology was the ease of access to the video and the ability 
to annotate it with a minimal learning curve. Two aspects of the annotations provided opportunities for teachers to reflect on their lessons. First, they annotated as they viewed the video; this served to mark moments the teacher felt were notable or productive for subsequent discussion with the coach. Second, before the debriefing meeting, they read the annotations made by the coach; this yielded additional insights into the lesson that were taken up in the debriefing session. Video allowed the teacher to view the moment referenced by the coach to gain a better understanding of the coach's observation and ensuing suggestion/question/wondering.

Second, annotations provided a window for coaches into teachers' thinking with regard to lesson implementation. Coaches typically read teachers' annotations of the video before making their own annotations. They commented that reading the annotations helped them to assess the teacher's noticing skills and to gauge the teacher's perceptions of the lesson.

Third, annotations provided an opportunity for asynchronous interaction between coach and teacher. Coaches and teachers would read, and sometimes respond to, each other's annotations in advance of the debriefing meeting.

Fourth, annotations served to structure debriefing meetings. Coaches and teachers frequently referenced the annotations during debriefing meetings, with questions posed by coaches in the annotations often a driving force. These purposes are described in more detail below, where we describe findings from interviews with coaches and from analysis of the annotations.

\section{Findings from Analysis Around Annotations}

Our analysis of coaches' annotations emerges from two distinct data sources. The first source entailed interviews of the coaches about the nature and purpose of their annotations and the second source was the annotations themselves. These two sources of data revealed patterns in the annotations and how they served the purposes noted above. We begin by describing five themes that emerged from the interviews, and then discuss patterns we noticed in our analysis of the annotations.

\section{Themes from Interviews with the Coaches}

Five primary themes emerged from interviews with coaches about their annotations. First, reading teachers' annotations provided insights into their thinking. Second, annotations provided an opportunity to interact with teachers in a way similar to a conversation. Third, coaches commented on the nature of their annotations. Fourth, coaches discussed how annotations structured the debriefing conversations. Fifth, coaches described the use of the notice-wonder pattern in their annotations and, similarly, how they used questions or wonderings as a means to push teachers to reflect on the lessons. We describe these themes in detail below.

Coaches described how reading teachers' annotations provided them insight into teachers' thinking around the lesson. Reiss described the annotation process as "an ongoing commentary" between teacher and coach. Hale explained how even a lack of annotation in a crucial moment helped her to understand the teacher's thinking. Whilton noted that annotations helped him to formatively assess a teacher, stating that an annotation "really, really illuminates where a teacher is at in their own development" and is "a real a good moment to recognize either it's a content knowledge thing or perhaps it's a that listening for, versus listening to, idea." Hale noted that annotations also provided insights into what the teacher wanted to discuss during the debriefing meeting.

The second theme was focused on annotations as an opportunity for coach and teacher to interact. McFarland explained that she used annotations to invite the teacher to elaborate on a 
moment of practice when they met for the debriefing discussion. Three coaches described how they crafted annotations in response to teachers' annotations. Hale and McFarland noted that they only annotated sections that the teacher had annotated. Whilton calibrated his annotations according to the tenor of the teacher's annotations. If the teacher was overly critical, he tried to find positive things to say, and he celebrated good moments.

The third theme involved the identification by coaches of moments they chose to annotate and how they chose to annotate them, particularly with respect to taking on an evaluative stance. Four coaches commented on their use of evaluative language. Reiss stated that she refrained from using evaluative language, saying she tries not to use language like "I really liked this," or, "really didn't' like this." Lowrey stated that she tries to ask about the impact of a teacher action rather than evaluating it: "Not just saying good job, or great question here, but the impact the question actually had." Alvarez similarly described how annotations provided an opportunity for non-evaluative feedback. She stated:

[the annotations] really have helped me to capture my thinking in a way that is not judgmental. I tried to not be judgmental, in terms of my conversation with them. I don't want to start things with, "I really liked when your blah, blah, blah." Trying to get away from, you know, "like" or "not like" as opposed to the noticings and wonderings help me think about, "I thought it was really impactful when you asked that question because then I noticed the students went back to work and were able to get further."

Alvarez, like many of the coaches, emphasized that those annotations were a place not to evaluate but to pose questions to teachers. Bishop, by contrast, stated that:

The first thing I look for is places where I can give some very positive feedback around something that I really liked and explain why I liked it, what it did for the lesson, what it did for a given student, whatever it happens to be.

Two coaches reported that they annotated the video when they noticed missed opportunities. Bishop stated "I look for places where a student did something really interesting, but maybe the teacher didn't notice it or the teacher ignored it or didn't use it to their advantage." Both Reiss and Bishop noted that they followed up on these annotations by asking the teacher what she would have done if they noticed what the coach did. Reiss stated:

Putting it back on the teacher and having that what-if out there. What would you have done? What could you have asked differently? What could you have done in that moment that might've changed the course of how that conversation went so that opens up and invites that conversation in our debriefing?

Coaches' description of the content of their annotations was evident in the annotations themselves. In particular, coaches' emphasis on using annotations to pose questions to the teacher based on something that they noticed, as summarized above, was clear in our analysis of the annotations, described below. See Table 2 for description of the themes and sub-themes.

\section{Table 2}




\section{Themes Generated from the Coaches' Interviews Regarding Annotations}

\begin{tabular}{|c|c|c|c|}
\hline Category & Sub-category & Description & Quote \\
\hline \multirow[t]{3}{*}{$\begin{array}{l}\text { Purpose of the } \\
\text { annotations for } \\
\text { the debriefing } \\
\text { discussion }\end{array}$} & $\begin{array}{l}\text { Annotations provide } \\
\text { insights into teacher } \\
\text { thinking }\end{array}$ & $\begin{array}{l}\text { The teachers' } \\
\text { annotations help the } \\
\text { coaches understand } \\
\text { what teachers notice } \\
\text { about their teaching }\end{array}$ & $\begin{array}{l}\text { What I get is that it's like an ongoing } \\
\text { commentary on what they-what } \\
\text { they're seeing. The teachers, their } \\
\text { annotations, I've found, the teachers } \\
\text { I've worked with, to just be pointing } \\
\text { something out to me, like, "Oh, so-and- } \\
\text { so wasn't getting it." Or, "Oh, I can't } \\
\text { believe they're working off task." }\end{array}$ \\
\hline & $\begin{array}{l}\text { Annotations are a } \\
\text { source of dialogue } \\
\text { between the teacher } \\
\text { and the coach }\end{array}$ & $\begin{array}{l}\text { The annotations allow } \\
\text { for some give-and-take } \\
\text { between the coach and } \\
\text { teacher }\end{array}$ & $\begin{array}{l}\text { I wonder what they were thinking when } \\
\text { they used this strategy because then } \\
\text { those are all talking points when we do } \\
\text { have our debrief of going through the } \\
\text { footage of the tagging and annotation } \\
\text { of, hey, let's talk about this section. I } \\
\text { was really curious about this. Tell me } \\
\text { what you were thinking when this } \\
\text { happened }\end{array}$ \\
\hline & $\begin{array}{l}\text { Annotations provide } \\
\text { structure for the } \\
\text { debriefing discussion }\end{array}$ & $\begin{array}{l}\text { The coaches directly } \\
\text { reference the } \\
\text { annotations in the } \\
\text { debriefing meetings to } \\
\text { guide the discussion }\end{array}$ & $\begin{array}{l}\text { In our final session, too, we kind of } \\
\text { went through together looking at the } \\
\text { annotations and comments and kind of } \\
\text { use those as a guide to the discussion. }\end{array}$ \\
\hline \multirow[t]{3}{*}{$\begin{array}{l}\text { Nature of } \\
\text { content of the } \\
\text { annotations }\end{array}$} & $\begin{array}{l}\text { Use of notice-wonder } \\
\text { pairings to provoke } \\
\text { teacher reaction to } \\
\text { specific moments of } \\
\text { practice }\end{array}$ & $\begin{array}{l}\text { The coach remarks on a } \\
\text { specific moment of } \\
\text { practice and then poses } \\
\text { a question to push the } \\
\text { teacher to reflect on that } \\
\text { moment of practice }\end{array}$ & $\begin{array}{l}\text { I would start, in a way, like this, like } \\
\text { with a factual statement about what I } \\
\text { see and then a push versus just a push. I } \\
\text { tried to let it be a-even if I felt like it } \\
\text { was an area for growth or an } \\
\text { opportunity, I started to find something } \\
\text { positive out of it. I've noticed this is } \\
\text { happening, yet also how could we push } \\
\text { for this to happen, too? }\end{array}$ \\
\hline & $\begin{array}{l}\text { Use of questions to } \\
\text { push teacher to } \\
\text { reflect on aspects of } \\
\text { practice }\end{array}$ & $\begin{array}{l}\text { Similar to the notice- } \\
\text { wonder pairing, the } \\
\text { teachers posed } \\
\text { questions to get } \\
\text { teachers to think about } \\
\text { their instructional } \\
\text { practices }\end{array}$ & $\begin{array}{l}\text { I will tend to say, "What could you } \\
\text { have asked in this situation that may } \\
\text { have changed what the student was } \\
\text { thinking?" Putting it back on the } \\
\text { teacher and having that what-if out } \\
\text { there. What would you have done? } \\
\text { What could you have asked } \\
\text { differently? What could you have done } \\
\text { in that moment that might've changed } \\
\text { the course of how that conversation } \\
\text { went so that opens up and invites that } \\
\text { conversation in our debriefing? }\end{array}$ \\
\hline & $\begin{array}{l}\text { Use of praise or } \\
\text { criticism }\end{array}$ & $\begin{array}{l}\text { The coaches described } \\
\text { how the refrained from } \\
\text { or purposefully used } \\
\text { evaluative language. }\end{array}$ & $\begin{array}{l}\text { Highlighting what they're doing, that's } \\
\text { effective. Not just saying good job, or } \\
\text { great question here, but what the } \\
\text { question actually the impact the } \\
\text { question actually had. Being able to } \\
\text { encourage and also provide } \\
\text { clarification around that, or elaboration } \\
\text { on that. }\end{array}$ \\
\hline
\end{tabular}




$\begin{array}{lll}\begin{array}{l}\text { Remarking on missed } \\ \text { opportunities }\end{array} & \begin{array}{l}\text { The coaches remarked } \\ \text { on instances when the } \\ \text { teacher missed an } \\ \text { opportunity to }\end{array} & \begin{array}{l}\text { Then, I go back and I look for missed } \\ \text { opportunities, in a way. I look for } \\ \text { places where, gee, a student did }\end{array} \\ & \begin{array}{l}\text { something really interesting, but maybe } \\ \text { trom student thinking }\end{array} & \begin{array}{l}\text { the teacher didn't notice it or -which } \\ \text { obviously, can happen to all of us -or } \\ \text { the teacher ignored it or didn't use it to } \\ \text { their advantage. }\end{array} \\ & \end{array}$

Patterns in the Anno We found patterns in coaches' annotations that reflected their purposes as well as coaching style. One of the stylistic patterns we observed emanated from the coaches' face to face experiences. Coaches engaged in notice-wonder pairing as discussed above. This pattern was evident to some degree across most of the coaches. Braithewhite wrote:

I think you were looking for the easiest area being the area of the wholes, students didn't seem to understand the question. Can you think of another way to ask? Is it an important question? Why or why not?

Braithewhite first noted that students had difficulty understanding one of the questions posed by the teacher during the lesson, and then provided a "wonder" in the form of several questions. Similarly, Bishop wrote:

You end the independent think time here and ask students to start talking to their group members. I was wondering about ways to structure the beginning small group discussions so that all students have a voice.

Bishop noted that the teacher transitioned from independent think time to group work without explicit instructions; she then posed a "wonder" about how to provide some initial structure to ensure that all students had an opportunity to participate. The "wonder" here bordered on a suggestion, as occurred in other cases that represented subtle variations on the notice-wonder pattern. McFarland, for example, wrote: "I like how you're trying to engage all of the learners. Maybe a turn and talk would help spark the conversation between smaller groups of students?" The notice statement is more of an evaluation and the wonder is more of a suggestion than a question. Another variation included a notice-question pattern, such as when Lowrey wrote:

I notice that you valued his input and connected it to a previous statement about fractions. What else would you like to know about Eric's thinking about his idea? It was recognized then a different conjecture became the focus.

After the noticing statement, Lowrey posed a question to provoke teacher reflection around an instructional practice.

All of the variations in the notice-wonder pattern entailed an observation from the coach about a specific moment of practice, with the "wonder" part serving as a stimulus for the ensuing conversation between the coach and the teacher. During the debriefing sessions, a substantive part of the discussion revolved around the annotations, particularly questions posed by the teachers in the form of a "wonder." 
In addition to the notice-wonder pattern, there were stylistic differences between coaches. Alvarez and Reiss, for example, had relatively more annotations coded as elicit than other coaches. By contrast, Bishop's annotations were more frequently coded as suggest or evaluate than other coaches; this difference was also evident in other aspects of the professional development project, suggesting that annotations provided a window into the coach's personal style.

In addition to finding differences between coaches' annotations, we also found differences between coaches' and teachers' annotations, particularly with respect to the valence of annotations we coded as evaluation. For the most part, when teachers' annotations were coded as evaluation, the teacher was highly critical of their practice. Conversely, the majority of coaches' annotations coded as evaluation were positive, praising particular aspects of the lesson, such as a productive question posed by the teacher, an insightful strategy from a student, or the timely use of a participation structure (e.g., turn and talk).

\section{Concluding Thoughts on Annotations}

The themes and findings regarding annotations demonstrate how the accessibility afforded by the Swivl system facilitated a set of interactions between coach and teacher that were not available in face-to-face coaching. The Swivl made it feasible to video-record lessons when the coach was physically distant from a teacher; furthermore, the ease of uploading and annotating facilitated highly productive interactions between coach and teacher.

A number of coaches commented on the affordances of having the video to facilitate reflection on the lesson. Hale stated:

I think having the video was really helpful because you're not relying on either the coach's or the teacher's recollection or interpretation of what happened. I also think having the opportunity to read the teacher's annotations and them having the opportunity to read my annotations allowed us potentially to start a little bit ahead in terms of a postconference than I would be able to in-person

McFarland similarly commented on the affordances of having video to focus the conversations with the teacher:

I think the video aspect of having that enhances those deeper conversations because you can both pull up the video, or you've already flagged the video, or you both have watched that again. That really connects you back to the work. I think that that's a huge plus to having the online coaching is to have that video to refer back to.

Having the opportunity to reflect asynchronously on the lesson provided opportunities for more deliberate use of language, particularly non-evaluative language, and for coaches to pose questions to teachers. The opportunity to craft language asynchronously and to be able to connect comments to specific moments of practice facilitated the development of teacher noticing and productive teacher-coach discussions. Based on our post-coaching interviews with teachers, doing content-focused coaching online led to a meaningful and trusting professional relationship with the coach. 


\section{Discussion}

We explored how a video-based online coaching model impacted coaches' ability to support teachers and to gauge the ways that features of the online environment afforded new opportunities for coaches and teachers to work together. We focused on two broad phases of coaching: planning the lesson and reflections on the enacted lesson. In the planning phase, we highlighted multiple practices employed by coaches and how those practices were revised to compensate for, or take advantage of, the online environment. In the reflection phase we focused on the nature and impact of annotations made by teachers and coaches on the video of the lessons stored in the Swivl library.

In terms of how the online environment afford new opportunities for coaches and teachers to work together, in the planning phase, coaches compensated for the lack of in-person contact by creating and relying on a digital template to gather information about lessons; this template structured the ensuing pre-lesson conference with the teacher. In addition, the template, and other lesson artifacts, were used by coaches to preview the mathematics and tasks to anticipate potential student responses and challenges. Furthermore, certain aspects of the online environment enhanced coaching, such as being able to share screens and collaboratively edit documents, providing more clarity in discussions.

In the reflection phase, we found that annotations structured the post-lesson reflection between coach and teacher, including the synchronous interactions between coach and teacher that took place in the post-lesson reflection meeting. Annotations served as an opportunity for formative assessment, as a place for asynchronous interaction between coach and the teacher, as a means to anticipate important topics in the post-lesson conference, and then as a means to structure the post-lesson conversation.

Prior research showing the effectiveness of online coaching primarily involved technical disciplines such as medicine and athletics (cf. Boyer et al, 2009, Hu et al., 2012), whereas prior research on online professional development for teachers showed limitations with respect to complex (e.g, non-technical) forms of learning (cf. Sing \& Khine, 2006). Our study, however, demonstrates that video-based coaching provided opportunities for coaches to engage teachers in complex practices related to planning and reflecting on mathematics lessons. The teachers in our study developed mathematical goals for student understanding, anticipated student strategies, and reflected on specific moments of lessons.

Similarly, prior studies of coaching had done little to document fine-grained accounts of practice (Gibbons \& Cobb, 2016, Stein et al., 2021). The online context provided an opportunity for us to explore interactions in all aspects of a coaching cycle in ways that would be difficult to accomplish in in-person settings. As a result, we documented a comprehensive set of planning practices that mirrored in-person coaching practices. Additionally, we found that video annotations were particularly valuable for structuring post-lesson reflections; there is no parallel to the annotations in settings that are in person.

As a final point of discussion, we note that the use of the Swivl robot was a particularly notable innovation. The robot allowed the teacher to video-record a lesson without assistance and upload the video with minimal effort. The coordination of the video file with the annotation system in Swivl facilitated the annotation process described above. The asynchronous nature of the reflection process allowed teachers time and repeated opportunities to reflect on specific moments in the lesson, which allowed for more deliberate identification of critical moments and use of evidence to guide reflections. 


\section{Conclusion}

Findings from this analysis yielded a set of coaching practices that coaches employed at various stages of the coaching cycle. These practices reveal what coaches $d o$ in each part of the coaching cycle as well as why they believe these practices will support teacher learning in a content-focused approach to coaching. Coaches' descriptions also give insight into the affordances and challenges of engaging in content-focused coaching in an online environment. Our findings showed that the online platform is not only an effective implementation for coaching, but also affords new opportunities for teacher reflection and evidence-based discussions. These findings are intended to inform professional development researchers and designers, mathematics coaches, and school administrators in making better decisions utilizing the online environment for coaching and how to scale up these programs to reach more teachers. In addition, the ability to conduct content-focused coaching online made it possible for coaches to work with teachers who were geographically distant; this enabled mathematics teachers who work in remote rural areas to have access to experienced coaches.

\section{Declarations}

The authors declared no potential conflicts of interest with respect to the research, authorship, and/or publication of this article.

The authors received approval from the ethics review board of the University of Rochester, USA for this study.

This research was supported in part by the National Science Foundation under Grant DRL1620911. 


\section{References}

Borko, H., Jacobs, J., Eiteljorg, E., \& Pittman, M. E. (2008). Video as a tool for fostering productive discussions in mathematics professional development. Teaching and Teacher Education, 24, 417-436. https://doi.org/10.1016/j.tate.2006.11.012

Boyer, E., Miltenberger, R., Batsche, C., \& Fogel, V. (2009). Video modeling by experts with expert feedback to enhance gymnastics skills. Journal of Applied Behavior Analysis, 42, 855860. https://doi.org/10.1901/jaba.2009.42-855

Calandra, B., Brantley-Dias, L., Lee, J. K., \& Fox, D. L. (2009). Using video editing to cultivate novice teachers' practice. Journal of Research on Technology in Education, 42(1), 73-94. https://doi.org/10.1080/15391523.2009.10782542

Campbell, P. F., \& Malkus, N. N. (2011). The impact of elementary mathematics coaches on student achievement. Elementary School Journal, 111(3), 430-454.

https://doi.org/10.1086/657654

Choppin, J., Amador, J., Callard, C., Carson, C., Gillespie, R., Kruger, J., Martin, S., \& Foster, G. (in press). A three-part synchronous online model for middle grades mathematics teachers' professional development. In K. Hollebrands, R. Anderson, \& K. Oliver (Eds.), Online learning in mathematics education. Springer.

Choppin, J., Amador, J., Callard, C., Carson, C., \& Gillespie, R. (2020). Synchronous online model for mathematics teachers' professional development. In S. Keengwe (Ed.), Handbook of research on online pedagogical models for mathematics teacher education. (pp. 176-202). IGI Global.

Cohen, D. K., \& Ball, D. L. (1999). Instruction, capacity, and improvement (RR-43). Correnti, R., Matsumura, L. C., Walsh, M., Zook-Howell, D., Bickel, D. D., \& Yu, B. (2021). Effects of online content-focused coaching on discussion quality and reading achievement: Building theory for how coaching develops teachers' adaptive expertise. Reading Research Quarterly, 56(3), 519-558. https://doi.org/10.1002/rrq.317

Davidson-Shivers, G. V., Muilenburg, L. Y., \& Tanner, E. J. (2001). How do students participate in synchronous and asynchronous online discussions? Journal of Educational Computing Research, 25(4), 351-366. https://doi.org/10.2190/6DCH-BEN3-V7CF-QK47

Dede, C., Ketelhut, D. J., Whitehouse, P., Breit, L., \& McCloskey, E. (2009). A research agenda for online teacher professional development. Journal of Teacher Education, 60(1), 8-19. https://doi.org/10.1177/0022487108327554

Fishman, B. J., Konstantopoulos, S., Kubitskey, B., Vath, R., Park, G., Johnson, H., \& Edelson, D. C. (2013). Comparing the impact of online and face-to-face professional development in the context of curriculum implementation. Journal of Teacher Education, 64(5), 426-438. 
Francis, K., \& Jacobsen, M. (2013). Synchronous online collaborative professional development for elementary mathematics teachers. International Review of Research in Open and Distance Learning, 14(3), 319-343. https://doi.org/10.19173/irrodl.v14i3.1460

Frederiksen, J. R., Sipusic, M., Sherin, M., \& Wolfe, E. W. (1998). Video portfolio assessment: Creating a framework for viewing the functions of teaching. Educational Assessment, 5(4), 225297. https://doi.org/10.1207/s15326977ea0504_1

Garrison, D. R., Anderson, T., \& Archer, W. (2001). Critical thinking, cognitive presence, and computer conferencing in distance education. American Journal of Distance Education, 15(1), 7 23.

Gaudin, C., \& Chalies, S. (2015). Video viewing in teacher education and professional development: A literature review. Educational Research Review, 16, 41-67. https://doi.org/10.1016/j.edurev.2015.06.001

Gibbons, L. K., \& Cobb, P. (2016). Content-focused coaching: Five key practices. The Elementary School Journal, 117(2), 237-260. https://doi.org/10.1086/688906

Gillespie, R., Amador, J., \& Choppin, J. (2019). Exploring the discursive differences of mathematics coaches within online coaching cycle conversations. In S. Otten, A. G. Candela, Z. de Araujo, C. Haines, \& C. Munter (Eds.), Proceedings of the forty-first annual meeting of the North American Chapter of the International Group for the Psychology of Mathematics Education (pp. 442-450). University of Missouri.

Haythornthwaite, C. (2000). Online personal networks: Size, composition, and media use among distance learners. New Media \& Society, 2(2), 195-226.

https://doi.org/10.1177/14614440022225779

Haythornthwaite, C. (2001). Exploring multiplexity: Social network structures in a computersupported distance learning class. The Information Society, 17, 211-226.

https://doi.org/10.1080/01972240152493065

Hrastinski, S. (2008). Asynchronous and synchronous e-learning. Educause Quarterly, 31(4), 5155.

Hu, Y., Peyre, S., Arriaga, A., Osteen, R., Corso, K., Weiser, G., Swanson, R., Ashley, S., Raut, C., Zinner, M., Gawande, A., \& Greenberg, C. (2012). Postgame analysis: Using video-based coaching for continuous professional development. Journal of the American College of Surgeons, 115-124.

Ippolito, J. (2010). Three ways that literacy coaches balance responsive and directive relationships with teachers. The Elementary School Journal, 111(1), 164-190.

https://doi.org/10.1086/653474 
Jacobs, J. K., \& Morita, E. (2002). Japanese and American teachers' evaluations of videotaped mathematics lessons. Journal for Research in Mathematics Education, 33(3), 154-175. https://doi.org/10.2307/749723

Johnson, C., \& Lock, J. (2018, March). Making multimedia meaningful: Outcomes of student assessment in online learning. In Society for Information Technology \& Teacher Education International Conference (pp. 1542-1549). Association for the Advancement of Computing in Education (AACE).

Keengwe, J., \& Kang, J. J. (2012). Blended learning in teacher preparation programs: A literature review. International Journal of Information and Communication Technology Education (IJICTE), 8(2), 81-93. https://doi.org/10.4018/jicte.2012040107

Knight, J., Bradley, B. A., Hock, M., Skrtic, T. M., Knight, D., Brasseur-Hock, I., Clark, J., Ruggles, M., and Hatton, C. (2012). Record, replay, reflect: Videotaped lessons accelerate learning for teachers and coaches. Journal of Staff Development, 33(2), 18-24.

Kraft, M. A., \& Hill, H. C. (2020). Developing ambitious mathematics instruction through webbased coaching: A randomized field trial. American Educational Research Journal, 57(6), 23782414. https://doi.org/10.3102/0002831220916840

Marra, R. M., Moore, J. L., \& Klimczak, A. K. (2004). Content analysis of online discussion forums: A comparative analysis of protocols. Educational Technology Research and Development, 52(2), 23-40.

McCreary, E. K. (1990). Three behavioral models for computer-mediated communication. In L. M. Harasim (Ed.), Online education: perspectives on a new environment (pp. 117-130). New York: Praeger.

Means, B., Toyama, Y., Murphy, R., Bakia, M., \& Jones, K. (2009). Evaluation of evidencebased practices in online learning: A meta-analysis and review of online learning studies. Project Report. Centre for Learning Technology.

Miles, M., Huberman, A., \& Saldaña, J. (2014). Qualitative data analysis: A methods sourcebook. Sage.

Pradarelli, J. C., Quamme, S. R. P., Yee, A., Faerber, A. E., Dombrowski, J. C., King, C., \& Greenberg, C. C. (2021). Surgical coaching to achieve the ABMS vision for the future of continuing board certification. The American Journal of Surgery, 221(1), 4-10. https://doi.org/10.1016/j.amjsurg.2020.06.014

Prusak, K., Dye, B., Graham, C., \& Graser, S. (2010). Reliability of pre-service physical education teachers' coding of teaching videos using Studiocode analysis software. Journal of Technology and Teacher Education, 18(1), 131-159. 
Rich, P., \& Hannafin, M. (2008). Decisions and reasons: Examining preservice teacher decisionmaking through video self-analysis. Journal of Computing in Higher Education, 20(1), 62-94. https://doi.org/10.1007/BF03033432

Russell, J. L., Correnti, R., Stein, M. K., Thomas, A., Bill, V., \& Speranzo, L. (2020). Mathematics coaching for conceptual understanding: Promising evidence regarding the Tennessee math coaching model. Educational Evaluation and Policy Analysis, 42(3), 439-466. https://doi.org/10.3102/0162373720940699

Scherer, L. A., Chang, M. C., Meredith, W., \& Battistella, F. D. (2003). Videotape review leads to rapid and sustained learning. The American Journal of Surgery, 185, 516-520. https://doi.org/10.1016/S0002-9610(03)00062-X

Sing, C. C., \& Khine, M. S. (2006). An analysis of interaction and participation patterns in online community. Educational Technology \& Society, 9(1), 250-261.

Sotillo, S. M. (2000). Discourse functions and syntactic complexity in synchronous and asynchronous communication. Language Learning \& Technology, 4(1), 82-119.

Stein, M. K., Russell, J. L., Bill, V., Correnti, R., \& Speranzo, L. (2021). Coach learning to help teachers learn to enact conceptually rich, student-focused mathematics lessons. Journal of Mathematics Teacher Education, 1-26. https://doi.org/10.1007/s10857-021-09492-6

Stockero, S. L., Rupnow, R. L., \& Pascoe, A. E. (2017). Learning to notice important student mathematical thinking in complex classroom interactions. Teaching and Teacher Education, 63, 384-395. https://doi.org/10.1016/j.tate.2017.01.006

Van Es, E. A., \& Sherin, M. G. (2002). Learning to notice: Scaffolding new teachers' interpretations of classroom interactions. Journal of Technology and Teacher Education, 10(4), 571-596.

Van Es, E. A., \& Sherin, M. G. (2008). Mathematics teachers' "learning to notice" in the context of a video club. Teaching and Teacher Education, 24(2), 244-276.

https://doi.org/10.1016/j.tate.2006.11.005

Vrasidas, C., \& Zembylas, M. (2004). Online professional development: Lessons from the field. Education + Training, 46(6/7), 326-334. https://doi.org/10.1108/00400910410555231

Walkoe, J. (2015). Exploring teacher noticing of student algebraic thinking in a video club. Journal of Mathematics Teacher Education, 18(6), 523-550.

Warschauer, M. (1995). Comparing face-to-face and electronic discussion in the second language classroom. CALICO Journal, 13(2), 7-26. 
West, L., \& Staub, F. C. (2003). Content-focused coaching: Transforming mathematics lessons. Heinemann.

Wilson, B. D. (2008). Development in video technology for coaching. Sports Technology, 1(1), 34-40. https://doi.org/10.1080/19346182.2008.9648449 